\section{Kidney \\ Blood Pressure Research}

\title{
Risk Factors of Renal Involvement Based on Different Manifestations in Patients with Ankylosing Spondylitis
}

\author{
Yan Wu ${ }^{a} \quad$ Guangli Zhang ${ }^{a}$ Niansong Wang ${ }^{a}$ Qin Xue \\ aDepartment of Nephrology, Shanghai Jiao Tong University Affiliated Sixth People's Hospital, Shanghai, \\ China
}

\section{Key Words}

Risk factors - Ankylosing spondylitis - Renal involvement - Different manifestations • Multivariable logistic regression analysis

\begin{abstract}
Background/Aims: Renal involvement is one of the most common extra-articular complications caused by ankylosing spondylitis (AS). Most studies have focused on the incidence rate, clinical manifestation and pathology, while risk factors have hardly been investigated. Therefore, the objective of this study was to assess the risk factors of renal involvement in patients with AS. Methods: Clinical and biochemical data of 926 AS patients were collected. Based on the manifestations of renal involvement, patients were divided into three groups and the differences in clinical and biochemical characteristics were compared. A group with non-renal involvement served as a control. Multivariable logistic regression was used for analyzing risk factors of renal involvement in AS. Results: Of the 926 AS patients, 201 patients suffered from renal involvement. Moreover, female AS patients faced a higher risk of hematuria compared to male patients. As indicated by the data obtained from multivariate logistic regression analysis, gender, uric acid (UA), immunoglobulin A (IgA), and serum albumin (ALB) were found to be risk factors of renal involvement in AS. An increase in UA or IgA levels, or a decrease in ALB level can increase the risk of renal involvement with multiple manifestations (more than one manifestation of renal damage). According to our findings, no definite variable was identified as a risk factor of proteinuria in AS patients. Conclusion: In AS patients, UA, IgA, and ALB levels can indicate the risk of renal involvement in AS patient and need to be paid special attention. Furthermore, women are subjected to a higher risk of hematuria.
\end{abstract}




\section{Kidney Blood Pressure Research}

\section{Introduction}

Ankylosing spondylitis (AS) is a type of chronic progressive inflammation with an incidence rate of $0.1-1.6 \%$ worldwide and $0.3 \%$ in China [1-2]. It mainly involves the sacroiliac joint but can invade peripheral joints, causing soft tissue ossification and joint fusion, which may ultimately lead to disability [3]. AS can also lead to severe extra-articular damage and involve multiple systems in the entire body. Renal involvement is one of most common extra-articular complications caused by AS, and accounts for $10-35 \%$ in AS patients [4]. The mortality rate is about $4 \%$.

At present, studies on renal involvement in AS are at the initial stages. Most studies have focused on incidence rate, clinical manifestation, and pathology [5], while little attention has been paid to its influencing factors. Previous studies have shown that gender, age, smoking, hypertension, hyperglycemia, renal structure, and drugs have an impact on renal function and are risk factors contributing to renal diseases, such as chronic renal disease, in the common population [6-9]. Moreover, additional studies have indicated uric acid (UA), C-reactive protein (CRP), and albumin (ALB) as risk factors causing renal diseases. In the common population as well as in glomerulonephritis patients, increasing UA levels are often seen in patients with renal involvement [10]. In addition, an increase in the level of inflammatory response marker CRP was closely related to deterioration of renal function. The CRP level in renal involvement patients is generally high [11]. Inflammatory responses have been related to relatively low levels of ALB [12], which is also the cause for a very high incidence of hypoalbuminemia in renal involvement patients. Studies on the abovementioned risk factors is based on renal diseases in the common population, however studies upon secondary renal involvement in AS patients is limited. The mechanism of renal involvement in AS is still unclear, and may be different from renal diseases in the common population. Therefore, the risk factors for patients with AS cannot be determined by prior studies.

Renal involvement is generally difficult to be perceived in clinical practice, and is often discovered by routine examination of AS patients, including hematuria, proteinuria, creatinine increase, or eGFR (estimated glomerular filtration rate) decrease in AS patients. When obvious symptoms occur in patients, the renal involvement has generally become very severe. Therefore, it is beneficial for AS patients to timely discover earlier signs of renal involvement. In this study, identifying risk factors on renal involvement with AS in 926 patients may provide a theoretical basis for timely discovering of secondary renal involvement, which is conducive to effectively preventing and controlling secondary renal involvement in AS patients in clinical.

\section{Materials and Methods}

\section{Patients}

From August 2003 - March 2015, data was collected from 1, 800 patients who were admitted for the first time to the Department of Nephrology of the Shanghai Jiao Tong University Affiliated Sixth People's Hospital (Shanghai, China), and were confirmed to have AS. A total of 926 AS patients were selected whose clinical and biochemical data set were complete.

Inclusion criteria: (1) patients who met the AS classification standard as established by the American College of Rheumatology (ACR) in 1984; (2) patients who were over 16 years old; (3) relevant data and records were timely collected, complete, and accurate; (4) no signs of diabetes, acute infection, tumors, or other primary renal diseases. 


\section{Kidney Blood Pressure Research}

Assessment indicators for renal disease

Renal involvement was indicated under one or more of the following circumstance(s).

(1) Microscopic proteinuria: $24 \mathrm{~h}$ urine protein $>0.2 \mathrm{~g}$;

(2) Microscopic hematuria: urine erythrocyte $>25 / \mu \mathrm{l}$;

(3) eGFR decrease: the guidelines of Kidney Disease Outcomes Quality Initiative (K/DOQI) and CKD (chronic kidney disease) diagnosis standard developed by the US (the United States) National Kidney Foundation are complied with, and the simplified MDRD (Modification of Diet in Renal Disease) formula is adopted to calculate eGFR.

In this study, patients who presented with an eGFR level lower than $60 \mathrm{~mL} / \mathrm{min} / 1.73 \mathrm{~m}^{2}$ were considered to experience decreased renal function.

\section{Research method}

Data measured and recorded at first hospitalization for AS treatment, concerning clinical features and biochemical data were collected and analyzed. Clinical features included gender, age, age of onset, age of diagnosis, course of disease, peripheral arthritis, medication history (NSAIDs (non-steroidal antiinflammatory drugs), DMARDs (disease-modifying anti-rheumatic drugs), and TNF- $\alpha$ (tumor necrosis factor $\alpha$ )). Biochemical data involved serum indicators (HLA-B27 (human leukocyte antigen B27), ESR (erythrocyte sedimentation rate), CRP, PLT (platelet), UA, IgG (immunoglobulin G), IgA (immunoglobulin A), IgM (immunoglobulin M), BUN (blood urea nitrogen), RBP (retinol binding protein), ALT (alanine aminotransferase), AST (aspartate transaminase), ALB, SCr (serum creatinine-for calculating eGFR)), and urine indicators (urine erythrocytes, and $24 \mathrm{~h}$ urine protein).

The 926 AS patients were divided into a renal involvement group and a non-renal involvement group, and the differences in indicators between both groups were analyzed. Next, inter-group differences between clinical and biochemical indicators of non-renal involvement patients were separately analyzed according to different clinical manifestations of renal involvement, such as hematuria, proteinuria, and multiple manifestations (more than one manifestation of renal damage: hematuria with proteinuria, or hematuria with decreased eGFR, or proteinuria with decreased eGFR, or hematuria-proteinuria-decreased eGFR). Finally, statistical regression analysis was conducted to evaluate the risk factors of renal involvement.

In addition, some patients with renal involvement have undergone renal biopsy, to determinate the pathological of renal damage. The pathological examination mainly was conducted by light microscopy, immunofluorescence and electron microscopy. The light microscope specimens (3um sections) were observed by HE (Hematoxylin-eosin), PAS (Periodic Acid-Schiff), Masson and Congo red staining respectively; the immunofluorescence examination used $4 \mathrm{um}$ frozen sections to observe the deposition and distribution of IgA, IgG and IgM; the electron microscopy was used to observe the deposition of ED (electron dense material).

\section{Statistical analysis}

SPSS 22.0 software was used for statistical analysis. Data were initially validated for normal distribution based on Kolmogorov-Smirnov, after which statistical analysis was carried out. Continuous variables were expressed as the mean \pm standard deviation (SD), while hierarchical variables were expressed as the number and percentage of patients. Inter-group comparison of continuous variables was performed through nonparameter analysis, while for hierarchical data $t$ test and Chi-square tests were performed to identify statistically different variables. For clinical observation indicators that showed a statistically significant difference, multivariate logistic regression was adopted to conduct risk factor correlation analysis, whereas the analysis results included odds ratio (OR), 95\% confidence interval (CI), and significance indicator P value. $\mathrm{P}<0.05$ was considered statistically significant.

\section{Results}

Characteristics of AS patients

The clinical characteristics of 926 AS patients are shown in Table 1. There were 760 male patients (82.1\%), which was significantly more than the 166 female patients $(17.9 \%)$ 


\section{Kidney \\ Blood Pressure Research}

Table 1. Characteristics of 926 AS patients. Except where indicated otherwise, values are in form of mean \pm SD. AS: Ankylosing Spondylitis; HLA-B27: human leukocyte antigen B27; Multiple manifestations: hematuria with proteinuria, or hematuria with decreased eGFR, or proteinuria with decreased eGFR, or hematuriaproteinuria-decreased eGFR

\begin{tabular}{lc}
\hline Variable & $\begin{array}{c}\text { All AS } \\
(\mathrm{n}=926)\end{array}$ \\
\hline Male/Female & $760 / 166$ \\
Age (years) & $30.96 \pm 10.92$ \\
Age of AS onset (years) & $26.04 \pm 10.22$ \\
Age of AS diagnosis (years) & $29.45 \pm 10.77$ \\
Disease duration (years) & $4.97 \pm 5.27$ \\
NSAIDS, $n(\%)$ & $265(29)$ \\
DMARDs, $n(\%)$ & $241(26)$ \\
TNF- $\alpha, \mathrm{n}(\%)$ & $61(7)$ \\
Peripheral arthritis, $\mathrm{n}(\%)$ & $498(54)$ \\
HLA-B27 positive, $\mathrm{n}(\%)$ & $873(94)$ \\
Manifestations of renal involvement in AS & \\
Hematuria, $\mathrm{n}(\%)$ & $132(14)$ \\
Proteinuria, $\mathrm{n}(\%)$ & $45(5)$ \\
Decreased eGFR, $\mathrm{n}(\%)$ & $1(0.1)$ \\
Multiple manifestations, $\mathrm{n}(\%)$ & $24(3)$ \\
\hline
\end{tabular}

Table 2. Pathological of renal involvement in 21 patients

\begin{tabular}{lcc}
\hline Renal pathological & Male & Female \\
\hline IgA nephropathy, $\mathrm{n}$ & 1 \\
Proliferative glomerulonephritis, $\mathrm{n}$ & 1 & 6 \\
Membranous nephropathy, $\mathrm{n}$ & 1 & 1 \\
Mild pathological glomerulonephritis, $\mathrm{n}$ & 1 & 0 \\
Acute interstitial nephritis, $\mathrm{n}$ & 0 & 1 \\
Sub-acute interstitial nephritis, $\mathrm{n}$ & 1 \\
Mesangial proliferative glomerulonephritis with Interstitial nephritis accompanied, $\mathrm{n}$ & 0 \\
\hline
\end{tabular}

who were selected in this study. The average age of AS onset was $26.04 \pm 10.22$ years, and the average course of disease was $4.97 \pm 5.27$ years. Roughly $60 \%$ of patients used drugs to treat AS, mainly NSAIDS and DMARDs, while a small number of patients used TNF- $\alpha$. In general, AS involved the axial joint, however we found that in about $54 \%$ of patients, involvement of peripheral joints was observed. There were 873 patients with positive HLA-B27 levels, accounting for $94.3 \%$. A total of 201 AS patients (21.7\%) suffered from renal involvement. Among those 201 patients, there were 132 hematuria patients (14.3\%), 44 proteinuria patients (4.9\%), 1 patient with eGFR decrease $(0.1 \%)$, and 24 patients with multiple clinical manifestations of renal involvement $(2.6 \%)$. These findings suggested that hematuria was the most common clinical manifestation of renal involvement.

Of the 201 renal involvement patients, 21 underwent a renal biopsy to determinate renal pathological. The results of the renal biopsy are shown in Table 2. We found that IgA nephropathy and Proliferative glomerulonephritis were the most common pathological types, accounted for $38 \%$ and $33.3 \%$ respectively.

\section{Comparisons of characteristics}

As shown in Table 3, in renal involvement patients, the average values of ESR and CRP in females were higher compared to that in non-renal involvement patients $23 \%$ vs $17 \% ; 48.95 \pm 33.84 \mathrm{~mm} / \mathrm{h}$ vs $42.07 \pm 31.02 \mathrm{~mm} / \mathrm{h} ; 29.12 \pm 33.51 \mathrm{mg} / \mathrm{L}$ vs $23.27 \pm 29.73$ $\mathrm{mg} / \mathrm{L}$ ). Moreover, the average values of UA, RBP, and ALB were lower compared to that in non-renal involvement patients $(309.39 \pm 79.13 \mu \mathrm{mol} / \mathrm{L}$ vs $321.78 \pm 83.05 \mu \mathrm{mol} / \mathrm{L} ; 33.65$ $\pm 11.86 \mu \mathrm{g} / \mathrm{mL}$ vs $36.05 \pm 11.95 \mu \mathrm{g} / \mathrm{mL} ; 43.16 \pm 4.54 \mathrm{~g} / \mathrm{L}$ vs $44.37 \pm 4.00 \mathrm{~g} / \mathrm{L})$, and these differences were statistically significant $(\mathrm{P}<0.05)$. Although in renal involvement patients age, age of onset, age of diagnosis, and disease duration were higher compared to non-renal involvement patients, the differences were not statistically significant. In addition, we found that positive HLA-B27 levels were very high in AS patients regardless of renal involvement (up to more than 93\%). To more accurately investigate the clinical and biochemical indicator differences between renal involvement patients and non-renal involvement patients in AS, 201 renal involvement patients were divided into three groups according to their different 


\section{Kidney \\ Blood Pressure Research}

Table 3. Comparisons of clinical and biochemical characteristics between renal involvement and nonrenal involvement in AS. Except where indicated otherwise, values are the mean \pm SD. ESR: erythrocyte sedimentation rate; CRP: C reactive protein; PLT: platelet; UA: uric acid; IgG: immunoglobulin G; IgA: immunoglobulin A; IgM: immunoglobulin M; BUN: blood urea nitrogen; RBP: retinol binding protein; ALT: alanine aminotransferase; AST: aspartate transaminase; ALB: serum albumin; $\mathrm{P}<0.05$ : statistically significant

\begin{tabular}{|c|c|c|c|}
\hline \multirow[b]{2}{*}{ Variable } & \multicolumn{2}{|c|}{ Renal involvement in AS } & \multirow[b]{2}{*}{$\mathrm{P}$} \\
\hline & $\begin{array}{c}\text { Yes } \\
(\mathrm{n}=201)\end{array}$ & $\begin{array}{c}\text { No } \\
(\mathrm{n}=725)\end{array}$ & \\
\hline \multicolumn{4}{|l|}{ Demographic characteristics } \\
\hline Gender, male, $\mathrm{n}(\%)$ & 154(77) & $605(83)$ & $<0.05$ \\
\hline Age (years) & $32.21 \pm 11.11$ & $30.61 \pm 10.86$ & 0.05 \\
\hline Age of onset (years) & $26.78 \pm 10.46$ & $25.84 \pm 10.15$ & 0.22 \\
\hline Age of diagnosis (years) & $30.79 \pm 11.17$ & $29.08 \pm 10.63$ & 0.06 \\
\hline \multicolumn{4}{|l|}{ Medical histories } \\
\hline NSAIDS, n(\%) & $55(27)$ & $209(29)$ & 0.72 \\
\hline DMARDs, n(\%) & $52(26)$ & $188(26)$ & 0.53 \\
\hline TNF- $\alpha, n(\%)$ & 14(7) & $46(6)$ & 0.75 \\
\hline \multicolumn{4}{|l|}{ Clinical manifestations } \\
\hline Disease duration (years) & $5.48 \pm 5.59$ & $4.82 \pm 5.17$ & 0.22 \\
\hline Peripheral arthritis n(\%) & 99(49) & 398(55) & 0.17 \\
\hline \multicolumn{4}{|l|}{ Biochemical indicators } \\
\hline HLA-B27 positive, n(\%) & 187(93) & 685(94) & 0.50 \\
\hline $\operatorname{ESR}(\mathrm{mm} / \mathrm{h})$ & $48.95 \pm 33.84$ & $42.07 \pm 31.02$ & $<0.05$ \\
\hline CRP (mg/L) & $29.12 \pm 33.51$ & $23.27 \pm 29.73$ & $<0.05$ \\
\hline $\operatorname{PLT}\left(10^{\wedge} 9 / \mathrm{L}\right)$ & $259.83 \pm 74.19$ & $258.64 \pm 76.90$ & 0.63 \\
\hline UA (umol/L) & $309.39 \pm 79.13$ & $321.78 \pm 83.05$ & $<0.05$ \\
\hline $\operatorname{IgG}(\mathrm{mg} / \mathrm{mL})$ & $15.02 \pm 3.72$ & $14.53 \pm 3.59$ & 0.06 \\
\hline $\operatorname{IgA}(\mathrm{mg} / \mathrm{mL})$ & $3.38 \pm 1.52$ & $3.10 \pm 1.27$ & 0.08 \\
\hline IgM (mg/mL) & $1.36 \pm 0.60$ & $1.33 \pm 0.58$ & 0.93 \\
\hline BUN (mmol/L) & $4.74 \pm 1.24$ & $4.63 \pm 1.19$ & 0.48 \\
\hline $\mathrm{RBP}(\mu \mathrm{g} / \mathrm{mL})$ & $33.65 \pm 11.86$ & $36.05 \pm 11.95$ & $<0.05$ \\
\hline $\operatorname{ALT}(\mathrm{u} / \mathrm{L})$ & $18.18 \pm 13.06$ & $19.44 \pm 13.12$ & 0.08 \\
\hline AST (u/L) & $18.09 \pm 5.65$ & $18.67 \pm 6.08$ & 0.15 \\
\hline $\operatorname{ALB}(\mathrm{g} / \mathrm{L})$ & $43.16 \pm 4.54$ & $44.37 \pm 4.00$ & $<0.05$ \\
\hline
\end{tabular}

clinical manifestations of renal involvement (Group 1: hematuria; Group 2: proteinuria; Group 3: multiple manifestations), and they were compared with non-renal involvement groups, respectively.

After renal involvement patients were divided into three groups (shown in Table 4), we determined other phenomena besides inter-group statistical differences in gender, ESR, CRP, UA, RBP, and ALB. Compared with non-renal involvement patients in AS hematuria, the proportion of male hematuria patients (Group 1) was smaller (71\% vs $83 \%$ ), and the age and the age of diagnosis was higher (33.16 $\pm 11.91 \mathrm{y}$ vs $30.61 \pm 10.86 \mathrm{y}, 31.82 \pm 12.03 \mathrm{y}$ vs $29.08 \pm 10.63$, respectively). In addition, the levels of UA, RBP, and ALB were lower (297.98 $\pm 74.52 \mu \mathrm{mol} / \mathrm{L}$ vs $321.78 \pm 83.05 \mu \mathrm{mol} / \mathrm{L}, 34.03 \pm 11.64 \mu \mathrm{g} / \mathrm{mL}$ vs $36.05 \pm 11.95 \mu \mathrm{g} / \mathrm{mL}$, $43.43 \pm 4.19 \mathrm{~g} / \mathrm{L}$ vs $44.37 \pm 4.00 \mathrm{~g} / \mathrm{L}$, respectively). In proteinuria patients (Group 2), CRP $(37.20 \pm 39.84 \mathrm{mg} / \mathrm{L}$ vs $23.27 \pm 29.73 \mathrm{mg} / \mathrm{L})$ and PLT $\left(286.72 \pm 79.5410^{\wedge} 9 / \mathrm{L}\right.$ vs $258.64 \pm$ $\left.76.9010^{\wedge} 9 / \mathrm{L}\right)$ levels were higher, whereas the RBP level was lower $(31.87 \pm 10.61 \mu \mathrm{g} / \mathrm{mL}$ vs $36.05 \pm 11.95 \mu \mathrm{g} / \mathrm{mL}$ ). Moreover, in patients with multiple renal involvement manifestations (Group 3), the IgA level was higher $(3.72 \pm 1.35 \mathrm{mg} / \mathrm{mL}$ vs $3.10 \pm 1.27 \mathrm{mg} / \mathrm{mL}$ ), whereas ALT, AST, and ALB levels were lower. Moreover, inter-group differences in the above-mentioned variables were statistically significant $(\mathrm{P}<0.05)$. We found that when compared with the non-renal involvement group, age, age of diagnosis, PLT, IgA, ALT, and AST levels were not significantly different between a single renal involvement groups, but showed a statistically significant difference between different types of renal involvement groups. Therefore, these variables were considered in the regression analysis. 


\section{Kidney Blood Pressure Research}

\section{Multivariable logistic regression analysis}

The above-mentioned variables that showed inter-group statistical differences were selected and multivariate logistic regression analysis was conducted. Table 5 shows the results of the analysis based on the different groups, in which only the variables identified as risk factors of renal involvement in AS are listed. As indicated by the analysis of the hematuria group (Group 1), gender was a risk factor of renal involvement in AS $(\mathrm{P}<0.05)$. Male AS patients had a lower risk of hematuria (OR: $0.568,95 \%$ CI: $0.340-0.949$ ). No statistically significant indicators were found after analysis of proteinuria patients (Group 2). Thus, no indicators were found that increase the risk of albuminuria in AS patient. In addition, according to the analysis of the patient group with multiple renal involvement manifestations (Group 3), UA, IgA, and ALB were recognized as risk factors of renal involvement in AS $(\mathrm{P}<0.05)$. The increase of UA or IgA level can increase the risk of occurring renal involvement with multiple clinical manifestations in AS patients (OR: 1.008, 95\% CI: 1.002-1.013; OR: 1.411, 95\% CI: 1.043-1.909), whereas a decrease in ALB levels also increase this risk in AS patients (OR: 0.802, 95\% CI: 0.718-0.896).

Table 4. Comparisons of clinical and biochemical characteristics between 3 different renal involvement groups and non-renal involvement group in AS. Except where indicated otherwise, values are the mean \pm SD. ESR: erythrocyte sedimentation rate; CRP: C reactive protein; PLT: platelet; UA: uric acid; IgG: immunoglobulin G; IgA: immunoglobulin A; IgM: immunoglobulin M; BUN: blood urea nitrogen; RBP: retinol binding protein; ALT: alanine aminotransferase; AST: aspartate transaminase; ALB: serum albumin; Groups with P $<0.05$ : The variables in those groups are statistically significant when those groups are compared with without renal involvement in AS; Group1= Hematuria; Group2= Proteinuria; Group3=Multiple manifestations of renal involvement

\begin{tabular}{|c|c|c|c|c|}
\hline Variable & $\begin{array}{l}\text { Group } 1 \\
(n=132)\end{array}$ & $\begin{array}{c}\text { Group } 2 \\
(n=45)\end{array}$ & $\begin{array}{c}\text { Group } 3 \\
(n=24)\end{array}$ & $\begin{array}{c}\text { Groups with } \\
\mathrm{P}<0.05 \\
\text { (vs without RI) }\end{array}$ \\
\hline \multicolumn{5}{|l|}{ Demographic characteristics } \\
\hline Gender, male, n(\%) & $94(71)$ & $41(91)$ & $19(79)$ & Group 1 \\
\hline Age (years) & $33.16 \pm 11.91$ & $30.18 \pm 10.21$ & $30.83 \pm 7.08$ & Group 1 \\
\hline Age of AS onset (years) & $27.77 \pm 11.38$ & $25.18 \pm 8.64$ & $24.33 \pm 7.38$ & \\
\hline Age of AS diagnosis (years) & $31.82 \pm 12.03$ & $28.40 \pm 10.08$ & $29.63 \pm 7.00$ & Group 1 \\
\hline \multicolumn{5}{|l|}{ Medical histories } \\
\hline NSAIDS, n(\%) & $39(30)$ & $10(22)$ & $6(25)$ & \\
\hline DMARDs, n(\%) & $35(27)$ & $12(27)$ & $5(21)$ & \\
\hline TNF- $\alpha, n(\%)$ & $10(8)$ & $3(7)$ & $1(4)$ & \\
\hline \multicolumn{5}{|l|}{ Clinical manifestations } \\
\hline Disease duration (years) & $5.47 \pm 5.84$ & $5.03 \pm 4.83$ & $6.40 \pm 5.65$ & \\
\hline Peripheral arthritis, n(\%) & $64(48)$ & $24(53)$ & $11(46)$ & \\
\hline \multicolumn{5}{|l|}{ Biochemical indicators } \\
\hline HLA-B27 positive, $n(\%)$ & 123(93) & $41(91)$ & 23(96) & \\
\hline $\operatorname{ESR}(\mathrm{mm} / \mathrm{h})$ & $46.81 \pm 32.24$ & $52.84 \pm 36.24$ & $53.41 \pm 38.04$ & \\
\hline $\mathrm{CRP}(\mathrm{mg} / \mathrm{L})$ & $27.59 \pm 32.03$ & $37.20 \pm 39.84$ & $22.41 \pm 26.38$ & Group 2 \\
\hline $\operatorname{PLT}\left(10^{\wedge} 9 / \mathrm{L}\right)$ & $252.93 \pm 69.59$ & $286.72 \pm 79.54$ & $247.39 \pm 79.56$ & Group 2 \\
\hline UA (umol/L) & $297.98 \pm 74.52$ & $323.34 \pm 82.58$ & $346.04 \pm 85.12$ & Group 1, \\
\hline $\operatorname{IgG}(\mathrm{mg} / \mathrm{mL})$ & $15.11 \pm 3.35$ & $15.27 \pm 4.14$ & $14.07 \pm 4.75$ & \\
\hline $\operatorname{IgA}(\mathrm{mg} / \mathrm{mL})$ & $3.33 \pm 1.59$ & $3.32 \pm 1.44$ & $3.72 \pm 1.35$ & Group 3 \\
\hline $\operatorname{IgM}(\mathrm{mg} / \mathrm{mL})$ & $1.34 \pm 0.57$ & $1.44 \pm 0.65$ & $1.30 \pm 0.65$ & \\
\hline $\mathrm{BUN}(\mathrm{mmol} / \mathrm{L})$ & $4.80 \pm 1.29$ & $4.62 \pm 1.08$ & $4.70 \pm 1.26$ & \\
\hline $\mathrm{RBP}(\mu \mathrm{g} / \mathrm{mL})$ & $34.03 \pm 11.64$ & $31.87 \pm 10.61$ & $34.88 \pm 15.05$ & Group 1,2 \\
\hline $\operatorname{ALT}(\mathrm{u} / \mathrm{L})$ & $17.58 \pm 12.21$ & $22.31 \pm 16.67$ & $13.75 \pm 6.89$ & Group 3 \\
\hline $\operatorname{AST}(\mathrm{u} / \mathrm{L})$ & $18.03 \pm 5.09$ & $19.22 \pm 6.74$ & $16.25 \pm 6.06$ & Group 3 \\
\hline $\operatorname{ALB}(\mathrm{g} / \mathrm{L})$ & $43.43 \pm 4.19$ & $43.22 \pm 4.87$ & $41.54 \pm 5.56$ & Group 1,3 \\
\hline
\end{tabular}

Table 5. Risk factors for renal involvement in AS through the multivariable logistic regression analysis. The reference group is non-renal involvement in AS (Table 3); SE: standard error; OR: odds ratio; CI: confidence interval; $\mathrm{P}<0.05$ : statistically significant

\begin{tabular}{|c|c|c|c|c|c|}
\hline Risk factors & B & SE & $\mathrm{P}$ & OR & $95 \% \mathrm{CI}$ \\
\hline \multicolumn{6}{|l|}{ Group 1} \\
\hline Gender/male & -0.566 & 0.262 & $<0.05$ & 0.568 & $0.340 \sim 0.949$ \\
\hline \multicolumn{6}{|c|}{ Group 2 (There is not variable with $\mathrm{P}<0.05$ ) } \\
\hline \multicolumn{6}{|c|}{ Group 3} \\
\hline UA & 0.008 & 0.003 & $<0.05$ & 1.008 & $1.002 \sim 1.013$ \\
\hline IgA & 0.344 & 0.154 & $<0.05$ & 1.411 & $1.043 \sim 1.909$ \\
\hline ALB & -0.220 & 0.056 & $<0.05$ & 0.802 & $0.718 \sim 0.896$ \\
\hline
\end{tabular}




\section{Kidney Blood Pressure Research}

Kidney Blood Press Res 2018;43:367-377

\begin{tabular}{l|l}
\hline DOI: $10.1159 / 000488071$ & (C) 2018 The Author(s). Published by S. Karger AG, Base
\end{tabular}

Published online: March 13, 2018

www.karger.com/kb

\section{Discussion}

In AS patients, the incidence of renal involvement including hematuria, proteinuria, decreased renal function, and decline in creatinine clearance rate increased from $10 \%$ to $35 \%$ [13]. Among the 926 AS patients in this study, 201 patients suffered from renal involvement, which accounted for $21.7 \%$. Among them, there were 132 hematuria patients (14.3\%), 45 proteinuria patients (4.8\%), and 24 patients with multiple renal involvement manifestations (2.6\%). At present, several studies have confirmed that gender, age, smoking, weight, hypertension, hyperglycemia, renal structure, drug, uric acid, CRP, and serum ALB levels are risk factors of renal involvement in the common population. To more accurately investigate the risk factors of renal involvement in AS patients, in this study, 201 renal involvement patients were divided into three groups according to different clinical manifestations. Based on the analysis of single factor inter-group difference, multivariate logistic regression analysis was conducted. We found that inter-group statistical differences $(\mathrm{P}<0.05)$ existed in variables as gender, age, age of diagnosis, CRP, PLT, UA, IgA, RBP, ALT, AST, and ALB levels. According to the multivariate regression analysis based on multiple factors, only gender, UA, IgA, and ALB were identified as risk factors of renal involvement in AS.

Although the findings of this study did not show that age was considered a risk factor of renal involvement in AS, it is indubitable that when age increases, the incidence of several diseases induces renal involvement, such as hypertension, diabetes, and other metabolismrelated diseases also increases. Previous studies [14-16] have indicated that renal vascular atherosclerosis was closely related to age and inflammation, and that an advanced age resulted in kidneys that were more sensitive to inflammation. In this study, factors such as age, age of onset, age of diagnosis, and course of disease were higher in renal involvement patients compared to non-renal involvement patients in AS. AS is an inflammatory disease, therefore, patients with advanced age and an extended course of disease have a longer inflammatory response, which increase the risk of renal involvement. Consequently, although this research has explicitly excluded the patients with these diseases, we cannot ignore the impact of age on renal involvement.

The male glomerular capillary is more sensitive to hormones and blood glucose levels, making it easier to increase blood capillary pressure and the risk of renal involvement [1718]. Female hormones can reduce the levels of prorenin, renin and plasma renin activity, change the hemodynamics of renal blood vessels, and mitigate the risk of renal involvement [19-20]. The above studies suggested that in the common population, males are more vulnerable to renal involvement. Moreover, previous studies indicated that the AS incidence was higher in men than women, with a ratio of 10:1 [21]. In this study, gender was confirmed to be a risk factor of renal involvement in AS $(\mathrm{P}<0.05)$. However, women had a higher risk of renal involvement with hematuria (B: -0.566, OR: 0.568, 95\% CI: 0.340-0.949). Our findings seemed to be inconsistent with that of prior studies. However, it cannot be overlooked that, among the patients with renal involvement in AS, the age of AS onset, age of diagnosis and course of disease were higher in female patients than in male patients (33.02 y vs $28.15 \mathrm{y}$, 37.58 y vs 32.26 y, 5.70 y vs 5.66 y, respectively). In fact, several studies [22] showed that the cause for female AS patients being more than male counterparts may be contributed to the fact that the symptoms seen in female patients were less typical compared with their male counterparts. In addition, in female patients the disease appeared to be less severe, making it easy to be missed and misdiagnosed. Thus, in women AS occurred at an older age, the age of diagnosis was delayed, and the course of disease was longer, making it more vulnerable to renal involvement. Therefore, clinically, more attention should be paid to renal involvement in senior female AS patients.

An increase in the serum UA level is usually accompanied by traditional metabolic cardiovascular diseases. Thus, for a long time, an increase in the UA level was not considered as a mark of metabolic disturbance. However, recent studies have shown that an increase 


\section{Kidney Blood Pressure Research}

in the serum UA level directly caused renal diseases [23]. Increasing serum UA levels can induce renal involvement through multiple mechanisms: the sedimentation of urate crystal leads to renal tuberculosis, and can produce pro-inflammatory effects, causing inflammation and tissue damage [24]. UA can promote the proliferation of vascular smooth muscle cells and endothelial cells, resulting in renal vascular sclerosis and deterioration of renal function $[23,25]$. An increase in UA levels can activate RAAS (renin-angiotensin-aldosterone system) to cause vasoconstriction and high pressure at the glomerulus, thereby increasing blood viscosity to form a thrombus [26]. Moreover, as shown by several studies, an increase in the level of UA is an independent risk factor of renal involvement, whether in animal models or in a healthy population, patients with hypertension, diabetes, or chronic renal diseases. According to this study, and excluding patients with hypertension, diabetes, or chronic renal diseases, serum levels of UA are a risk factor of renal involvement in AS. An increase in serum UA level may increase the risk of renal involvement with multiple manifestations in AS patients (B: 0.008, OR: 1.008, 95\% CI: 1.002-1.013). In addition, an increase in UA and renal involvement promotes each other. Renal arteriosclerosis and glomerulonephritis can lead to UA glomerulus filtration and decreasing kidney tubule secretion, thereby increasing the serum UA level.

The content of IgA in normal human serum is only next to that of IgG, and accounts for $10-20 \%$ of the total content of serum immunoglobulins. Based on its immune function, IgA can be divided into two types: a serum type and a secretory type. Serotype IgA accounts for about $85 \%$ of total IgA, but it does not appear to have an important immune function. In this study, however, the IgA level referred to serum IgA. The results showed that the level of serum IgA in patients with renal involvement was significantly higher compared to that in patients without renal involvement. Especially for renal involvement in patients with multiple manifestations, IgA levels were about $20 \%$ higher in patients without renal involvement. Additional analysis of risk factors suggested that serum IgA was a risk factor for renal involvement in AS patients. Indeed, the higher the IgA level, the more likely AS patients were to suffer from multiple manifestations of renal involvement (B: 0.344, OR: 1.411, 95\% CI: 1.043-1.909). Based on the findings described above, we can assume that in AS patients, serum IgA does not form circulating immune complexes, which precipitate in the kidneys of these patients and cause kidney damage. On the other hand, it demonstrates the cause of IgA nephropathy in AS patients. Previous studies have shown that IgA nephropathy is most commonly found in renal involvement in AS, and accounts for about 30\% [27]. Serotype IgA is associated with elevated secretion of IgA, whereas secretory IgA is the major antibody found in the secretory fluid, which is involved in local mucosal protection. Studies have shown that there is a negative correlation between the activity of secretory IgA and AS disease, and that a higher level of secretory IgA, correlates with a lower activity of AS [28]. Therefore, we concluded that in AS patients, increased serum levels of IgA were associated with increased secretion of secretory IgA and neutralizing antigen, thereby becoming a risk factor for renal involvement in AS.

The relation between hypoproteinemia and renal involvement was demonstrated in previous studies [29]. As shown previously, the causes for hypoproteinemia (rather than hypoproteinemia itself) can lead to a high incidence and high mortality in hemodialysis patients. Hypoproteinemia frequently occurs in CKD patients [30], and recent studies have demonstrated that hypoproteinemia is a risk factor for renal development [31]. In IgA renal disease, hypoproteinemia is an independent risk factor that contributes to its poor prognosis [32]. Our findings showed that serum ALB is a risk factor of renal involvement in AS patients. AS patients with decreasing ALB levels are more vulnerable to renal involvement with multiple clinical manifestations (B: -0.128, OR: 0.880, 95\% CI: 0.799-0.968), which is related to the function of serum ALB. Serum ALB usually reflects the nutritional status and the internal inflammatory response of a patient, however, most AS patients are young and middle-aged and the incidence of malnutrition is relatively low. As indicated, the decrease in serum ALB levels is closely related to chronic progressive inflammation in AS patients. 


\section{Kidney \\ Blood Pressure Research}

Moreover, it has been shown that long-term chronic inflammation plays an important role in renal involvement in AS patients.

We suggested that when AS patients, especially senior females, received diagnosis and treatment, attention should be paid to the levels of UA, IgA, and ALB. Once abnormalities have been detected, patients should be screened early to prevent secondary renal involvement. Our study showed that, when compared with other variables, gender was the risk factor with the greatest impact, and its regression coefficient reached 0.566. Moreover, IgA and ALB levels were also risk factors with great impact, and their regression coefficients were 0.344 and 0.220 , respectively. UA levels were closely related to the activity of AS, however, the regression coefficient of was only 0.008 . Therefore, we cannot underestimate the role of the inflammatory response in the process of renal involvement in AS patients.

In the presence of high risk factors, we advised the patient to actively treat AS [33], avoid drugs that are harmful to the kidney, take a nutrition-balanced diet, exercise regularly, and avoid too much work. In addition, we recommend regular follow-ups for renal function and urine biochemistry. Once abnormalities were detected, we advised the patient to immediately seek specialized care and undergo renal biopsy if necessary to determine the type of lesion and to decide on corresponding treatment measures.

In the future, we will conduct additional studies with a larger sample size to study this phenomenon. Furthermore, a more extensive longitudinal study will be required to explore the mechanism of action, which governs the renal involvement in AS, and the results obtained in this study will be validated from the biological perspective.

\section{Disclosure Statement}

All test methods in this paper have been permitted by the Ethics Committee. All presented results were never submitted or published in any journal or meeting.

\section{Acknowledgements}

The author extraordinarily thanks the Department of Nephrology of Shanghai Jiao Tong University Affiliated Sixth People's Hospital for providing the opportunity to collect patient data. Special thanks also go to Professor Qin Xue for offering helpful advice in preparing this paper.

\section{References}

1 Hukuda S, Minami M, Saito T, Mitsui H, Matsui N, Komatsubara Y, Makino H, Shibata T, Shingu M, Sakou T, Shichikawa K: Spondyloarthropathies in Japan: nationwide questionnaire survey performed by the Japan Ankylosing Spondylitis Society. J Rheumatol 2001;28:554-559.

-2 Bakland G, Nossent HC, Gran JT: Incidence and prevalence of ankylosing spondylitis in Northern Norway. Arthritis Rheum 2005;53:850-855.

- Wang Y, Luo J, Wang X, Yang B, Cui L: MicroRNA-199a-5p Induced Autophagy and Inhibits the Pathogenesis of Ankylosing Spondylitis by Modulating the mTOR Signaling via Directly Targeting Ras Homolog Enriched in Brain (Rheb). Cellular Physiol Biochem 2017;42:2481-2491.

-4 Vilar MJ, Cury SE, Ferraz MB, Sesso R, Atra E: Renal abnormalities in ankylosing spondylitis. Scand J Rheumatol 1997;26:19-23.

5 Lee SH, Lee EJ, Chung SW, Song R, Moon JY, Lee SH, Lim SJ, Lee YA, Hong SJ, Yang HI: Renal involvement in ankylosing spondylitis: prevalence, pathology, response to TNF-a blocker. Rheumatol Int 2013;33:16891692.

-6 Silbiger S, Neugarten J: Gender and Human Chronic Renal Disease. Gend Med 2008;5:S3-S10. 


\section{Kidney \\ Blood Pressure Research}

7 Orth SR, Stöckmann A, Conradt C, Ritz E, Ferro M, Kreusser W, Piccoli G, Rambausek M, Roccatello D, Schäfer K, Sieberth HG, Wanner C, Watschinger B, Zucchelli P: Smoking as a risk factor for end-stage renal failure in men with primary renal disease. Kidney Int 1998;54:926-931.

8 Mittal A, Sathian B, Kumar A, Chandrasekharan N, Sunka A: Diabetes mellitus as a Potential Risk Factor for Renal Disease among Nepalese. Nepal J Epidemiol 2010;1:22-25.

-9 Perneger TV, Klag MJ, Whelton PK: Recreational Drug Use: A Neglected Risk Factor for End-Stage Renal Disease. Am J Kidney Dis 2001;38:49-56.

10 Viazzi F, Leoncini G, Ratto E, Pontremoli R: Serum Uric Acid as a Risk Factor for Cardiovascular and Renal Disease: An Old Controversy Revived. J Clin Hyprtens (Greenwich) 2006;8:510-518.

$>11$ Westhuyzen J, Healy H: Review: Biology and Relevance of C-Reactive Protein in Cardiovascular and Renal Disease. Ann Clin Lab Sci 2000;30:133-143.

$\checkmark 12$ De Mutsert R, Grootendorst DF, Indemans F, Boeschoten EW, Krediet RT, Dekker FW, Netherlands Cooperative Study on the Adequacy of Dialysis-II Study Group: Association Between Serum Albumin and Mortality in Dialysis Patients Is Partly Explained by Inflammation, and Not by Malnutrition. J Ren Nutr 2009;19:127-135.

13 Strobel ES and Fritschka E: Renal diseases in ankylosing spondylitis: review of the literature illustrated by case reports. Clin Rheumatol 1998;17:524-530.

14 Dalbeni A, Giollo A, Tagetti A, Atanasio S, Orsolini G, Cioffi G, Ognibeni F, Rossini M, Minuz P, Fava C, Viapiana O: Traditional cardiovascular risk factors or inflammation: Which factors accelerate atherosclerosis in arthritis patients? Int J Cardiol 2017;236:488-492.

15 Dehghan P, Rajaei A, Moeineddin R, Alizadeh AM: Prevalence of atherosclerosis in patients with inactive rheumatoid arthritis. Clin Rheumatol 2015;34:1363-1366.

16 Arida A, Zampeli E, Konstantonis G, Fragiadaki K, Kitas GD, Protogerou AD, Sfikakis PP: Rheumatoid arthritis is sufficient to cause atheromatosis but not arterial stiffness or hypertrophy in the absence of classical cardiovascular risk factors. Clin Rheumatol 2015;34:853-859.

-17 Cherney DZ, Sochett EB, Miller JA: Gender differences in renal responses to hyperglycemia and angiotensinconverting enzyme inhibition in diabetes. Kidney Int 2005;68:1722-1728.

18 Miller JA, Anacta LA and Cattran DC: Impact of gender on renal response to angiotensin II. Kidney Int 1999:55:278-85.

19 Baiardi G, Macova M, Armando I, Ando H, Tyurmin D, Saavedra JM: Estrogen upregulates renal angiotensin II AT1 and AT2 receptors in the rat. Regul Pept 2005;124:7-17.

20 Gallagher PE, Li P, Lenhart JR, Chappell MC, Brosnihan KB: Estrogen regulation of angiotensin-converting enzyme mRNA. Hypertension 1999;33:323-328.

21 Gran JT, Husby G: Ankylosing Spondylitis in Women. Med J Aust 1990;19:308-309.

22 Feldtkeller E, Bruckel J, Khan MA: Scientific contributions of ankylosing spondylitis patient advocacy groups. Curr Opin Rheumatol 2000;12:239-247.

-23 Johnson RJ, Kang DH, Feig D, Kivlighn S, Kanellis J, Watanabe S, Tuttle KR, Rodriguez-Iturbe B, HerreraAcosta J, Mazzali M: Is there a pathogenetie role for uric acid in hypertension and cardiovascular and renal disease? Hypertension 2003;41:1183-1190.

-24 Roncal CA, Mu W, Croker B, Reungjui S, Ouyang X, Tabah-Fisch I, Johnson RJ, Ejaz AA: Effect of elevated serum urie acid on cisplatin-induced acute renal failure. Am J Physiol Renal Physiol 2007;292:116-122.

25 Mazzali M, Kanellis J, Han L, Feng L, Xia YY, Chen Q Kang DH, Gordon KL, Watanabe S, Nakagwa T, Lan HY, Johnson RL: Hypemrieemia induces a primary renal arteriolopathy in rats by a blood pressure independent mechanism. Am J Physiol Renal Physiol 2002;282:991-997.

-26 Sánchez-Lozada LG, Tapia E, Santamaría J, Avila-Casado C, Soto V, Nepomuceno T, Rodríguez-Iturbe B, Johnson RJ, Herrera-Acosta J: Mild hyperuricemia induces vasoconstriction and maintains glomerular hypertension in normal and remnant kidney rats. Kidney Int 2005;67:237-247.

-27 Levy AR, Szabo SM, Rao SR, Cifaldi M, Maksymowych WP: Estimating the occurrence of renal complications among persons with ankylosing spondylitis. Arthritis Care Res (Hoboken) 2014;66:440-445.

28 Salas-Cuestas F, Bautista-MolanoW, Bello-Gualtero JM, Arias I, Castillo DM, Chila-Moreno L, Valle-Oñate R, Herrera D, Romero-Sánchez C: Higher levels of secretory iga are associated with low Disease activity index in Patients with reactive arthritis and Undifferentiated spondyloarthritis. Front Immunol 2017;8:476. 


\section{Kidney \\ Blood Pressure Research}

29 Kim YO, Yoon SA, Ku YM, Yang CW, Kim YS, Kim SY, Choi EJ, Chang YS, Bank BK: Serum Albumin Level Correlates with Disease Severity in Patients with Hemorrhagic Fever with Renal Syndrome. J Korean Med Sci 2003;18:696-700.

30 Uchikawa T, Shimano M, Inden Y, Murohara T: Serum Albumin Levels Predict Clinical Outcomes in chronic kidney disease (CKD) Patients Undergoing Cardiac Resynchronization Therapy. Intern Med 2014;53:555561.

-31 Kubo S, Kitamura A, Imano H, Cui H, Yamagishi K, Umesawa M, Muraki I, Kiyama M, Okada T, Iso H, Circulatory Risk in Communities Study Investigators Group: Serum Albumin and High-Sensitivity C-reactive Protein are Independent Risk Factors of Chronic Kidney Disease in Middle-Aged Japanese Individuals: the Circulatory Risk in Communities Study. J Atheroscler Thromb 2016;23:1089-1098.

-32 Le WB, Liang SS, Hu Y, Deng K, Bao H, Zeng C, Liu Z: Long-term renal survival and related risk factors in patients with IgA nephropathy: results from a cohort of 1155 cases in a Chinese adult population. Nephrol Dial Transplant 2012;27:1479-1485.

-33 Wang Y, Wang H, Jiang J, Zhao D, Liu Y: Comparative Efficacy and Acceptability of Anti-TNF-Alpha Therapy in Ankylosing Spondylitis: A Mixed-Treatments Comparison. Cell Physiol Biochem 2016;39:1679-1694. 